\title{
TWO NEW INEQUALITIES FOR GAUSSIAN AND GAMMA DISTRIBUTIONS
}

\author{
XIAO-LI HU
}

Abstract. Two new inequalities regarding $Q$ function and incomplete upper bound Gamma function are established, which are related to Gaussian and Gamma distributions respectively.

Mathematics subject classification (2010): 33B20, 26D15.

Keywords and phrases: Q function, upper incomplete gamma function, Gaussian distribution, Gamma distribution.

\section{REFERENCES}

[1] A. BARICZ, A functional inequality for the survival function of the Gamma distribution, J. Inequal. Pure and Appl. Math., 9, 1 (2008), Article 13.

[2] P. Natalini and B. Palumbo, Inequalities for the incomplete Gamma Function, Mathematical Inequalities \& Applications, 3, 1 (2000), 69-77. 